\title{
A Leukocyte Homologue of the IL-8 Receptor CXCR-2 Mediates the Accumulation of Macrophages in Atherosclerotic Lesions of LDL Receptor-deficient Mice
}

\author{
William A. Boisvert, ${ }^{\star}$ Robert Santiago, ${ }^{\ddagger}$ Linda K. Curtiss, ${ }^{\star}$ and Robert A. Terkeltaub $¥ \S$ \\ *The Scripps Research Institute, La Jolla, California 92037; the ${ }^{\ddagger}$ VA Medical Center, San Diego, California 92161; and the ${ }^{\S}$ Stein Institute \\ for Research on Aging, University of California San Diego, La Jolla, California 92093
}

\begin{abstract}
Chronic macrophage-mediated inflammation is central to atherosclerosis. A role of the monocyte chemotactic and activating $\mathrm{C}-\mathrm{C}$ chemokine JE/monocyte chemotactic protein-1 has been proposed. However, the human $\mathrm{C}-\mathrm{X}-\mathrm{C}$ chemokines growth-regulated oncogene $(\mathrm{GRO} \alpha)$ and IL-8, and their shared receptor, CXCR-2, also can be expressed at sites of chronic inflammation. Because we detected CXCR-2 in the intima of human atherosclerotic lesions, we examined the role of leukocyte CXCR-2 expression in affecting lesion cellularity. Atherosclerosis-susceptible LDL receptor-deficient mice were irradiated, successfully repopulated with bone marrow cells that either lacked or expressed mIL-8RH (the homologue of CXCR-2), and fed an atherogenic diet for 16 wk. In recipients of mIL-8RH $+/+$ marrow, mIL-8RH colocalized with densely accumulated intimal MOMA-2 positive macrophages. In contrast, lesions in recipients of mIL-8RH-I- marrow lacked mIL-8RH, had little intimal MOMA-2 staining, and were less extensive. The mIL-8RH ligand $\mathrm{KC} / \mathrm{GRO} \alpha$ was detected in the intima of all aortic atherosclerotic lesions. Thus, the capacity of leukocytes to express $\mathrm{mIL}-8 \mathrm{RH}$, and associated intralesional expression of its ligands such as $\mathrm{KC} / \mathrm{GRO} \alpha$, mediated the intimal accumulation of macrophages in atherosclerotic lesions of LDL receptor-deficient mice. (J. Clin. Invest. 1998. 101:353-363.) Key words: atherogenesis - inflammation - bone marrow transplantation • chemokines • GRO $\alpha$
\end{abstract}

\section{Introduction}

A chronic inflammatory response to injury is a central feature of atherosclerosis (1) and may serve as a prognostic marker for heightened risk of myocardial infarction (2). Monocyte-macrophages and activated $\mathrm{T}$ lymphocytes that can recognize intralesional antigens accumulate and colocalize in atherosclerotic lesions of all stages $(3,4)$. The role of $\mathrm{T}$ cells in atherogenesis is currently unresolved (5-9). However, it is known that the products of activated macrophages are critical

This work was submitted in abstract form for presentation at the 1997 American Heart Association National Meetings.

Address correspondence to Robert Terkeltaub, M.D., VA Medical Center, 3350 La Jolla Village Drive, San Diego, CA 92161. Phone: 619-552-8585, ext. 3519; FAX: 619-552-7425; E-mail: rterkeltaub@ ucsd.edu

Received for publication 14 July 1997 and accepted in revised form 11 November 1997.

The Journal of Clinical Investigation

Volume 101, Number 2, January 1998, 353-363

http://www.jci.org for not only the development of atherosclerotic lesions, but also their progression and superimposed thrombotic complications (1).

The ingress, retention, and activation of mononuclear leukocytes in atherogenesis are the sequelae of atherogenic insults that induce the expression of certain endothelial adhesion molecules for leukocytes and the release of a variety of inflammatory mediators that can activate and chemoattract leukocytes $(1,10)$. These include certain products of lipid oxidation that are released from LDL (11-15), and several mediators released from cells, such as M-CSF and JE/monocyte chemotactic protein-1 (MCP-1) ${ }^{1}(1)$.

$\mathrm{JE} / \mathrm{MCP}-1$ is a member of a subfamily of chemokines, designated as $\mathrm{C}-\mathrm{C}$ because of the spacing of the first two of four conserved cysteines (16), whose members generally chemoattract monocytes and/or lymphocytes. JE/MCP-1 is abundant in atherosclerotic lesions, and it stimulates monocytes to express IL-1 in vitro, and induces monocyte chemotaxis and adhesion to endothelium (16). Furthermore, JE/MCP-1 is a major mediator of oxidized LDL-stimulated monocyte transmigration through the endothelium $(14,15)$.

Members of the other major chemokine subfamily, the C-X-C chemokines (e.g., IL-8, growth-regulated oncogene [GRO $\alpha$ ], interferon $\gamma$-inducible protein-10 [IP-10], and platelet factor $4[\mathrm{PF} 4])$, are predominantly recognized as chemoattractants of neutrophils and/or lymphocytes $(17,18)$. Nevertheless, the potential role in atherogenesis of IL-8 and other members of a subset of the C-X-C chemokines that bind the IL-8 receptor CXCR-2 (including GRO $\alpha$ and neutrophil activating protein-2 [NAP-2]) $(17,18)$ is receiving increasing attention. In this regard, IL- 8 is expressed by lesional macrophage-derived foam cells and by other cell types at several different stages of the human atherosclerotic process (19-21). Proatherogenic-oxidized LDL not only stimulates cultured endothelial cells, monocytic cells, and vascular smooth muscle cells to express JE/MCP-1 (15), but also induces substantial IL-8 expression by monocyte-macrophages (22), and the expression of a GRO gene by rabbit endothelial cells in vitro (23). Cholesterol-loaded macrophages express IL-8 in vitro in a particularly abundant and long-lived manner relative to expression of other cytokines (20). Furthermore, other atherogenic insults can promote the production of additional CXCR2-binding chemokines. For example, thrombin induces endothelial cells to express GRO $\alpha$ in vitro (24), and the catabolism of $\beta$-thromboglobulin released by activated platelets can generate NAP-2 (16).

IL-8 is a potent endothelial cell chemoattractant and

1. Abbreviations used in this paper: BMT, bone marrow transplantation; G3PDH, glyceraldehyde-3-phosphate dehydrogenase; GRO, growth-regulated oncogene; LDLR-/-, LDL receptor-deficient; MCP-1, monocyte chemotactic protein-1; NAP-2, neutrophil activating protein-2; RT-PCR, reverse transcriptase-PCR. 
growth factor (25). Furthermore, functional IL-8 receptors are normally expressed on circulating $\mathrm{T}$ cells and monocytes (26-32). Determinations of the fractions of mononuclear leukocytes expressing IL- 8 receptors, and the numbers of IL- 8 receptors on normal mononuclear leukocytes have varied substantially between laboratories (26-32). Although it has been consistently observed that IL-8 receptors are far less numerous on mononuclear leukocytes than on neutrophils $(28,29)$, IL-8 and GRO $\alpha$ can chemoattract IL-8 receptor-expressing T lymphocytes in vitro $(26,27)$. Furthermore, IL-8 has been documented to modulate transendothelial $\mathrm{T}$ cell migration into certain inflammatory skin lesions in vivo $(31,33,34)$.

Functional significance of IL-8 receptor expression by monocytes also has been demonstrated. A surface-bound rabbit GRO gene, expressed by endothelium exposed to minimally modified LDL, markedly increases the ability of monocytes to adhere to endothelium in vitro (23). IL-8 also has the capacity to modulate monocyte-endothelial adhesion in vitro $(35,36)$. The effects of IL-8 on the adhesion of monocytes appear to be mediated in part by rapid stimulation of the activation states (and the ability to bind selected matrix constituents) of specific leukocyte integrins $(34,35)$.

The potential effects of IL-8 receptor-binding C-X-C chemokines on the function on monocytes and monocytederived macrophages do not appear to be limited to adhesion, because IL- 8 and GRO $\alpha$ stimulate both signal transduction and increased NADPH oxidase activity in normal peripheral blood monocytes (37). Furthermore, expression of the IL-8 receptor CXCR-2 can be highly regulated by several inflammatory agonists, including LPS in vitro $(38,39)$, and CXCR-2 appears to be inducible in a subset of macrophages in chronic experimental dermal granulation tissue in vivo (40).

In view of the collective observations cited above, we studied the impact of the responsiveness of mononuclear leukocytes to IL-8 receptor-binding C-X-C chemokines in atherosclerosis. One means of blocking the potentially redundant effects on leukocytes of IL-8 receptor-binding C-X-C chemokines is to inhibit the activity of CXCR-2 (16-18). In this regard, CXCR-2 is more promiscuous than the homologous human IL-8 receptor CXCR-1, which binds only IL-8 and GCP-2 with high affinity $(12,13)$. In contrast, a subgroup of human C-X-C chemokines that includes IL-8, GRO $\alpha$, GRO $\beta$, GRO $\gamma$, granulocyte chemotactic protein (GCP-2), epithelial neutrophil activator-78 (ENA-78), and NAP-2 (17) share structural features (41) that mediate high affinity binding to CXCR-2 $(17,18)$. Similarly, the murine IL-8 receptor homologue of human CXCR-2 (mIL-8RH) (12), acts as a promiscuous high affinity receptor for IL-8 and GRO gene products $(43,44)$.

Despite the existence of another mouse gene that has partial homology to the human IL-8 receptor CXCR-1 $(44,45)$, mIL-8RH is unequivocally the sole murine receptor on neutrophils that functionally binds IL- 8 and the murine GRO gene homologues KC/GRO $\alpha$ and MIP-2/GRO $\beta, \gamma$ (43). Furthermore, mice homozygous for deletion of mIL-8RH (mIL$8 \mathrm{RH}-/-$ ) retain intact chemotactic responses to non-chemokine agonists (e.g., FMLP, C5a), but do not demonstrate leukocyte chemotaxis to the IL-8 receptor-binding subgroup of C-X-C chemokines in vitro or in vivo (42). Thus, to evaluate the potential role that IL-8 receptor-binding C-X-C chemokines might play in the localization of mononuclear leukocytes to atherosclerotic lesions, we have engrafted mIL-8RH-/- bone marrow cells (the precursors of peripheral leukocytes) into irradiated LDL receptor-deficient (LDLR-/-) mice, which are susceptible to diet-induced atherosclerosis $(46,47)$.

The LDLR - / - model was chosen because allogeneic wildtype bone marrow-derived mononuclear leukocytes provided by transplantation are found in atherosclerotic lesions in marrow recipient LDLR-/- mice (47). Furthermore, the ability of LDLR - / - mice to develop atherosclerotic lesions is not affected by the provision of normal leukocyte-specific LDL receptors by bone marrow transplantation (47).

Our studies demonstrated that mIL-8RH/CXCR-2 and $\mathrm{KC} / \mathrm{GRO} \alpha$ are present in atherosclerotic lesions, and provided the first in vivo evidence for a role of mIL-8RH/CXCR-2 and its ligands in modulating both the lesional accumulation of intimal macrophages, and the extent of lesions in atherosclerosis.

\section{Methods}

Animals. Breeding pairs of mice heterozygous (mIL-8RH-/+) for knockout of the IL-8 receptor homologue, backcrossed onto the C57BL/6J background, were obtained from Dr. Mark Moore and Dr. Grace Cacalano of Genentech (South San Francisco, CA) (27). LDLR - / - mice $(46,47)$ also backcrossed onto the C57BL/6J background were initially obtained from The Jackson Laboratory (Bar Harbor, ME). All mice were weaned at $4 \mathrm{wk}$ and were initially fed ad libitum using a chow diet (diet \#5015; Harlan Teklad, Madison, WI). Mice were maintained and bred under a 12-h light-dark cycle in specific pathogen-free conditions that included housing in autoclaved filter-top cages and irradiation of food (42).

$P C R$. To identify homozygous mIL-8RH $-/-$ or mIL- $8 \mathrm{RH}+/+$ littermates, we analyzed genomic DNA of offspring at 3 wk of age. To do so, tail clippings were digested at $55^{\circ} \mathrm{C}$ for $18 \mathrm{~h}$ in a lysis buffer containing $1 \mathrm{mg} / \mathrm{ml}$ proteinase $\mathrm{K}, 0.5 \%$ SDS, $100 \mathrm{mM} \mathrm{NaCl}, 50 \mathrm{mM}$ Tris- $\mathrm{HCl}, 7.5 \mathrm{mM}$ EDTA, $\mathrm{pH}$ 8.0. Genomic DNA was purified using $2.5 \mathrm{M} \mathrm{LiCl}$ and precipitated in isopropanol on ice, and then resuspended in TE buffer (10 mM Tris-HCl, pH 8.0/1 mM EDTA, pH 8.0). The genomic DNA was amplified in a single tube 35 cycle PCR reaction using a validated set of specific primers for the wild type mIL8RH (5' CCTCGTACTGCGTATCCTGCCTCAG 3' and 5' TAGCCATGATCTTGAGAAGTCCATG $3^{\prime}$ ) which do not amplify with the Neomycin resistance gene insertion, and the primers $5^{\prime}$ CGGTTCTTTTTGTCAAGAC $3^{\prime}$ and $5^{\prime}$ ATCCTCGCCGTCGGGCATGC 3', which detect the Neomycin resistance gene insertion $(42,43)$.

For reverse transcriptase-PCR (RT-PCR), total RNA was isolated from peripheral blood leukocytes, separated from red blood cells by hypotonic lysis, at 4 wk after bone marrow transplantation (BMT), and from spleens dissected from all mice at time of death, using the methods previously described (47). The methods and conditions for reverse transcription also are detailed elsewhere (47), and the PCR protocol for mIL-8RH detection in cDNA is described above. Glyceraldehyde-3-phosphate dehydrogenase (G3PDH) mRNA was coamplified to serve as a positive control.

BMT and atherogenic diet. 24 6-wk-old male LDLR-/- mice were subjected to $1,000 \mathrm{rad}$ of total body irradiation to eliminate most of the bone marrow-derived cells, including stem cells (47). Marrow cells used for repopulation of the irradiated mice were isolated from either a 6-wk-old male mIL-8RH-/- mouse or mIL-8RH +/+ littermate, by previously described methods (47). Irradiated LDLR-/mice that received $2 \times 10^{6}$ marrow cells (injected into the tail vein) from the mIL-8RH-/- donor mouse were designated IL-8RH-/BMT mice), and recipients of an equal number of marrow cells from the wild-type littermate mouse were designated IL- $8 \mathrm{RH}+/+$ BMT mice). After BMT, the mice were placed on a chow diet for $4 \mathrm{wk}$, after which an atherogenic diet containing $15.8 \%$ (wt/wt) fat and $1.25 \%$ cholesterol (no cholate) (diet \#94059; Harlan Teklad), was given for $16 \mathrm{wk}$, followed by killing. 
The animals were bled at week 0 (before BMT), and 4, 8 , and 20 wk after BMT and total cholesterol was analyzed on plasma samples isolated using a kit from Sigma Chemical Co. (St. Louis, MO). To do so, blood was drawn into heparin-coated capillary tubes (Baxter Healthcare Corp., McGraw Park, IL) after a 6-h fast by retro-orbital puncture under Metofane-induced anesthesia. Plasma was separated from peripheral blood cells by centrifuging the blood samples at 3,000 $\mathrm{g}$ for 30 minutes at $4^{\circ} \mathrm{C}$. Plasma pooled from all mice in each group also was subjected to FPLC for separation of lipoprotein fractions, as previously described $(47,48)$. All animal procedures were institutionally reviewed and in accordance with accepted guidelines.

Assessment of atherosclerosis in aortas and aortic valves. Details of the preparation of aortas and aortic valves are described in detail elsewhere $(47,48)$. In brief, the aortas were dissected out, opened longitudinally, and stained with Sudan IV for visual assessment of the extent of atherosclerosis and photographed. The valve sections of the heart were used to quantify lesion areas in a defined region of the aortic valve. In brief, the OCT-embedded hearts were sectioned in a cryostat until all three leaflets were visible within the aortic valve. From this point, $10 \mu \mathrm{m}$ sections were taken for the next $300 \mu \mathrm{m}$ of the valve region, and each section was collected on a Superfrost slide (Fisher Scientific, Tustin, CA). The lipid-rich lesions were visualized by staining the sections with oil red $\mathrm{O}$ followed by counterstaining with hematoxylin. A total of five sections taken every $40 \mu \mathrm{m}$ was used to quantitate lesion areas using a computer-assisted video imaging system (49). The average lesion area of the five sections from each heart was taken to represent one animal, and the means of the average lesion areas from each group were compared.

Immunohistochemistry. Human atherosclerotic lesions were obtained as leftover material at carotid endarterectomy and were embedded in OCT medium and snap-frozen in liquid nitrogen. Cryo-stat sections $(3-5 \mu \mathrm{m})$ were acetone-fixed and blocked with nonimmune rabbit serum before incubation with a poyclonal rabbit antibody specific for human CXCR-2 (50) (from Dr. I. Schraufstatter, The Research Institute of Scripps Clinic, La Jolla, CA). Mouse atherosclerotic lesions were assessed immunohistochemically using a polyclonal rabbit anti-mouse mIL-8RH (Chemicon International, Inc., Temecula, CA), a polyclonal goat anti-mouse KC (R \& D Systems, Minne- apolis, MN), a polyclonal rat antibody to the mouse monocyte-macrophage marker MOMA-2 (51) (Serotec Ltd., Kidlington, Oxford, United Kingdom), and rabbit polyclonal antibodies to $\alpha$-actin and murine CD4 and CD8 (Life Technologies, Gaithersburg, MD).

The heart and artery tissue cryo-sections used for immunohistochemical staining were fixed in acetone at $-20^{\circ} \mathrm{C}$ for $2 \mathrm{~min}$ and immersed in PBS for 5 min to rehydrate the tissues. All further incubations were performed at room temperature in a humid chamber, except for the incubation with primary antibodies. The biotin in the sections was blocked by incubating in avidin for $15 \mathrm{~min}$, washing and then reincubating in biotin for $15 \mathrm{~min}$. The sections were incubated in $5 \%$ normal sera (matched for the antibodies to KC, mIL-8RH, MOMA-2, murine CD4 and CD8, $\alpha$-actin, and human CXCR-2) diluted in $0.5 \%$ BSA in PBS (PBS/BSA) for $30 \mathrm{~min}$. The tissues were incubated in a $10 \mu \mathrm{g} / \mathrm{ml}$ dilution of the primary antibodies overnight at $4^{\circ} \mathrm{C}$. After a thorough washing, the sections were incubated with their respective secondary antibodies at $5 \mu \mathrm{g} / \mathrm{ml}$ (biotinylated goat anti-rabbit IgG for mIL-8RH and biotinylated rabbit anti-goat IgG for $\mathrm{KC}$, MOMA-2, murine CD4 and CD8, $\alpha$-actin, and human CXCR-2 (both from Vector Laboratories, Inc., Burlingame, CA). Endogenous peroxidase was blocked at this point with a blocking agent (Zymed, South San Francisco, CA) for 2 min. The sections were incubated with Vectastain ABC Elite solution (Vector Laboratories, Inc.) for $30 \mathrm{~min}$. At this point, the staining method differed for $\mathrm{mIL}-8 \mathrm{RH}$ and $\mathrm{KC}$ because of differences in staining intensities. Staining for mIL-8RH was achieved by developing the sections with 9-amino-3-ethylene-carbazole (AEC) or diaminobenzidine (DAB) (Vector Laboratories, Inc.) after the Vectastain step. For KC staining the signal was enhanced using Tyramide Signal Amplification kit (New England Nuclear, Boston, MA) as recommended by the manufacturer. This was done by incubating with 1:50 dilution of biotinyl tyramide for $8 \mathrm{~min}$ after the initial Vectastain incubation, followed by another incubation with Vectastain and development with AEC. All sections were counterstained with hematoxylin and mounted with an aqueous mounting medium (Shandon Lipshaw, Pittsburgh, PA).

Statistical analysis. Statistical significance was determined using analysis of variance (ANOVA) and the Mann-Whitney $U$ test, where indicated.
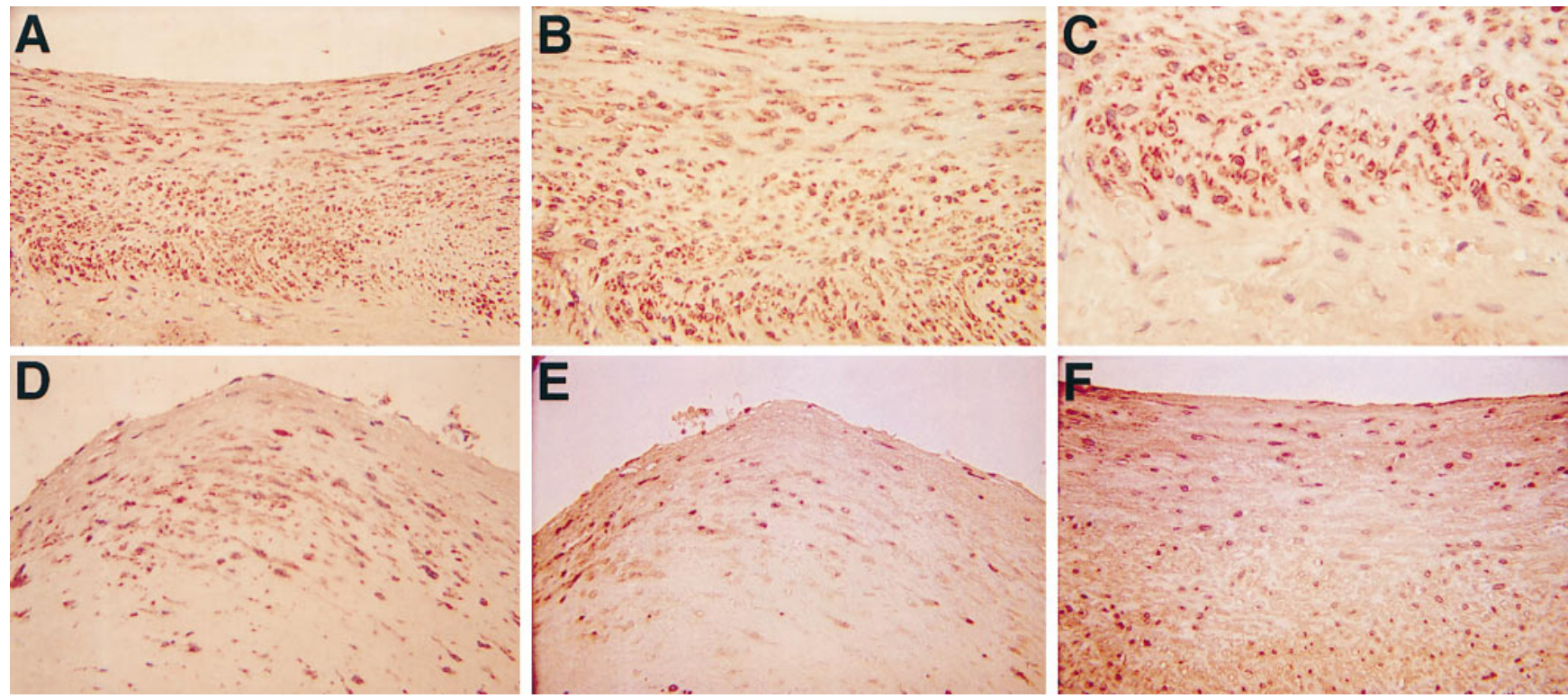

Figure 1. Detection of the IL-8 receptor CXCR-2 in human carotid endarterectomy atherosclerotic lesions. Cryo-sections from atherosclerotic lesions from different subjects were studied by immunohistochemistry, as described in Methods. Subject A, $A-C$ and $F$; subject B, $D-E$. $A-D$ were stained with a rabbit polyclonal antiserum specific for human CXCR-2; $E$ and $F$ were stained with an irrelevant control antibody $(A, \times 50)$; $B$ and $D-F(\times 130)$; and $C(\times 200)$. Positive (red) staining of CXCR-2 in the lesions ( $A$ and $D)$ was localized to cells within the intima $(B$ and $C)$. 


\section{Results}

CXCR-2 can be present in the intima of human atherosclerotic lesions. CXCR-2 was detected by immunohistochemistry in the intima of two out of two human carotid artery atherosclerotic lesions examined (Fig. 1). It was localized predominantly to the intima in regions that are commonly populated with macrophages (1). This detection of CXCR-2 in human atherosclerotic lesions prompted us to examine the role of CXCR-2 in leukocyte localization in atherosclerotic lesions. We chose to study a murine model, in which the bone marrow of mice deficient in the CXCR-2 homologue mIL-8RH were used to repopulate irradiated atherosclerosis-susceptible LDLR-/mice.

Effects of BMT and an atherogenic diet. Leukocyte repopulation from respective BMT donors was confirmed by observing expression of mIL-8RH mRNA in the spleen and the peripheral blood leukocytes (PBL) of BMT recipients. Fig. 2 shows a representative result of RT-PCR for mIL-8RH in splenic mRNA of three animals (at the time of death) from the mIL-8RH+/+ BMT group and four from the mIL-8RH-/BMT group, using G3PDH as a positive control. The PBL of all recipients of mIL-8RH $+/+$ BMT expressed mIL-8RH mRNA, whereas all recipients of mIL-8RH-/- BMT were negative for mIL-8RH mRNA by 4 wk after BMT (data not shown).

Plasma cholesterol values from individual mice at various times are shown in Fig. 3. Mean cholesterol levels were similar between the two groups at week 0 (after BMT) and was mod-

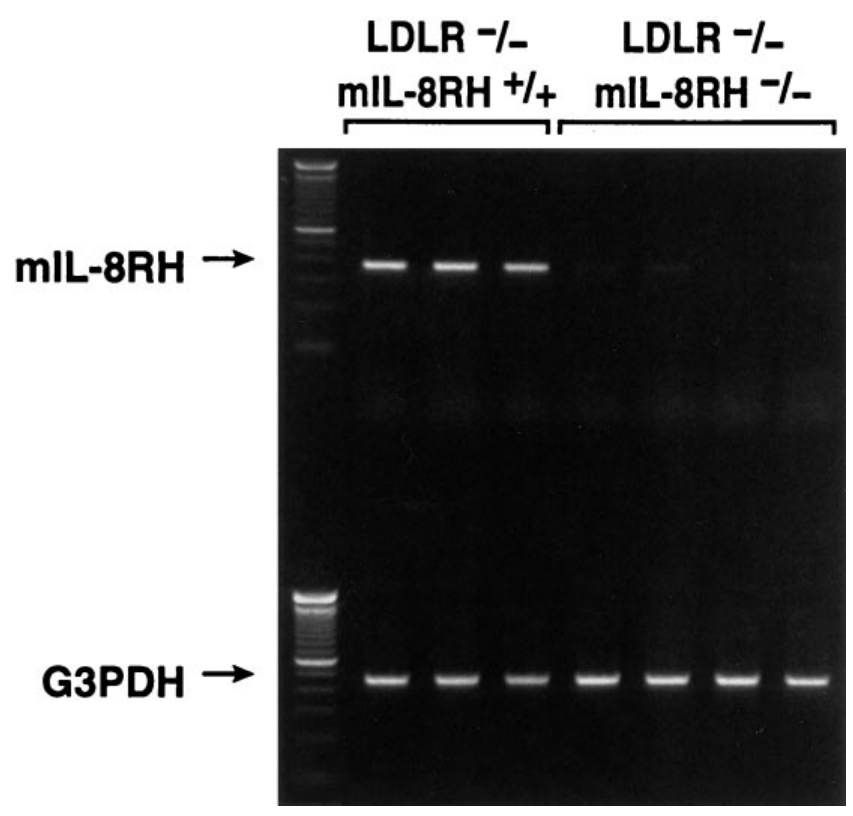

Figure 2. Transplantation with mIL-8RH-/- bone marrow repopulates splenic leukocytes with donor leukocytes in LDLR-/- recipients. RT-PCR results of RNA isolated from spleen of three representative recipients of $\mathrm{mIL}-8 \mathrm{RH}+/+\mathrm{BMT}$ and four representative recipients of mIL-8RH-/- BMT are shown. RNA from the tissues was reverse transcribed using random primers and amplified for 30 cycles with primers that detect wild-type mIL-8RH mRNA, but not the mutant mRNA. G3PDH primers were used as positive control, as seen by the bands on the lower portion of the gel.

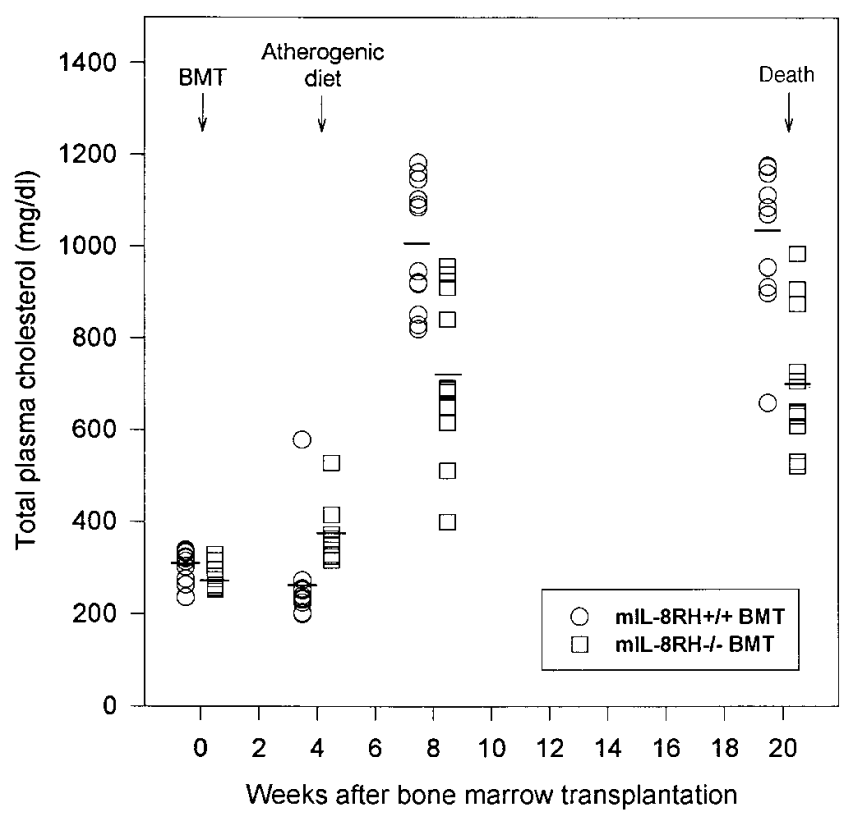

Figure 3. Total plasma cholesterol before (Pre-BMT) and 4, 8, and 20 wk after bone marrow transplantation (Post-BMT). The mice were given a standard chow diet until $4 \mathrm{wk}$ post-BMT (open symbols) and then switched to the atherogenic diet for an additional $16 \mathrm{wk}$. Thus, 8 wk post-BMT and $20 \mathrm{wk}$ post-BMT values represent plasma cholesterol in mice fed the atherogenic diet for 4 and $16 \mathrm{wk}$, respectively. Each symbol represents fasting plasma cholesterol of individual mice transplanted with either wild-type BMT (circles, $n=12$ ) or mIL$8 \mathrm{RH}-/-\mathrm{BMT}$ (squares, $n=11$ ). The mean \pm SD plasma cholesterol values $(\mathrm{mg} / \mathrm{dl})$ for mIL-8RH+/+ BMT and mIL-8RH-/- BMT groups were: $307 \pm 33$ and $272 \pm 27$ (week 0); 264 \pm 101 and $366 \pm 60$

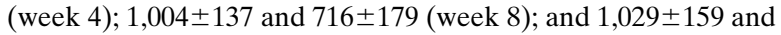
$705 \pm 153$ (week 20).

estly elevated in the mIL-8RH-/- BMT group at week 4 (after BMT) while the animals were on a chow diet. Plasma cholesterol levels increased several-fold from baseline levels, as expected $(46,47)$, when the animals were placed on the atherogenic diet. Mean plasma cholesterol at $8 \mathrm{wk}$ on the atherogenic diet was $29 \%$ lower in the mIL-8RH-/- BMT mice compared with their mIL- $8 \mathrm{RH}+/+$ BMT counterparts, and was $31 \%$ lower at the time of death (16 wk after institution of the atherogenic diet). FPLC analysis revealed that this difference in plasma cholesterol was due to differences in all lipoprotein fractions, particularly VLDL (Fig. 4).

At the time of death, the mIL-8RH-/- BMT mice had splenomegaly and a lack of splenic germinal centers, consistent with the previously demonstrated defect in the ability to constrain myeloid lineage expansion in the mIL-8RH-/- phenotype $(42,52)$. At the time of death, the coats of mIL-8RH-/BMT mice also had lost some of their sheen, and these mice consistently weighed $\sim 15 \%$ less than their counterparts that had received normal bone marrow.

Lesion analysis. To visually assess the extent of atherosclerosis in killed mice, aortas were dissected, opened longitudinally, and stained with Sudan IV to render the neutral lipids bright red. Six animals (three per group) that had similar plasma cholesterol values between $910-957 \mathrm{mg} / \mathrm{dl}$ were chosen 


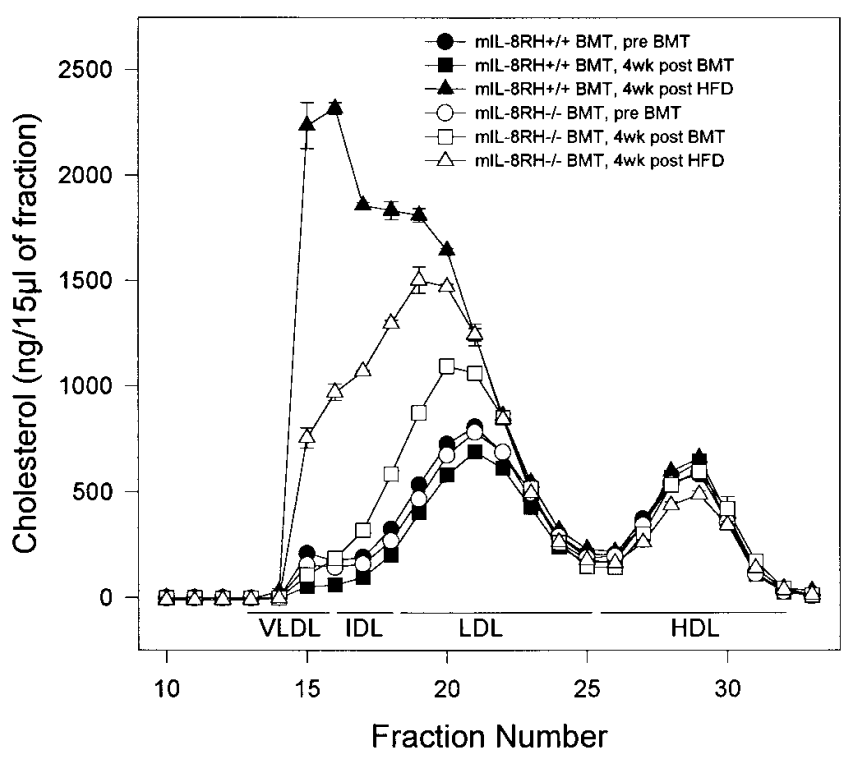

Figure 4. FPLC separation of the LDLR-/- mouse plasmas on Superose 6 (HR 10/30 column) to reveal the distribution of cholesterol among the various lipoprotein fractions. Plasma fractions were pooled for each time point in equal proportions from all mice within each group and $0.1 \mathrm{ml}$ was applied to the column. Cholesterol in each $0.5 \mathrm{ml}$ fraction was measured by a fluorometric enzyme assay. The data indicates the relative cholesterol content of each $0.5 \mathrm{ml}$ FPLC fraction.

for this analysis. Although there was visible variability in the extent of atherosclerosis, particularly among the three aortas from the mIL-8RH+/+ BMT mice (Fig. 5, left), the lesions were clearly less extensive in the three mIL-8RH-/- BMT mice (Fig. 5, right). This was particularly evident when the arch regions (at the left end of each aorta) of the two groups were compared.

Further analysis of the aortic valve sinus of the hearts with oil red O-stained serial sections of the frozen hearts also revealed notably smaller and less advanced lesions in the mIL-8RH-/- BMT mice. These small lesions were characterized by a less prominent necrotic core and by less smooth muscle cell proliferation (Fig. 6, $C$ and $D$, compared with the control mIL-8RH+/+ mice in $A$ and $B$ ).

Quantitative comparison of lesion size. Computer-assisted video imaging of similarly oil red $\mathrm{O}$-stained aortic valve lesions, serially sectioned from frozen hearts as described above, was used to quantify lesion areas. The results (Fig. 7) confirmed the qualitative evidence for reduction in lesion areas in mice lacking expression of the mIL-8RH in leukocytes after BMT (Fig. 6). In Fig. 7, where each point represents the mean lesion area of five valve sections quantified from each mouse, it is demonstrated that the mean lesional area of the mIL$8 \mathrm{RH}+/+$ BMT mice was $654,241 \pm 99,117 \mu \mathrm{m}^{2}, n=12$, compared with $249,581 \pm 147,197 \mathrm{um}^{2}$ for the mIL-8RH-/- BMT mice, $n=11$ ( $P=0.00008$ by the Mann-Whitney test).

Because the two groups of mice also differed on the basis of plasma cholesterol on an atherogenic diet after BMT (f $1 / 21=24.03, P<0.0001$ by ANOVA), further analysis was necessary. Although the variance between the two groups for lesion size was even more substantial (f $1 / 21=60.78, P<$
0.0001 by ANOVA), a direct relationship between cholesterol and lesion size was evident when all the animals of both groups were included in the analysis. Nevertheless, a subgroup analysis of those animals that had comparable plasma cholesterol values after BMT proved significant. Specifically, we identified animals in both groups that had an average plasma cholesterol at 8 and $20 \mathrm{wk}$ between 780 and $960 \mathrm{mg} / \mathrm{dl}$. In this regard, the mean plasma cholesterol values were $894 \pm 67 \mathrm{mg} / \mathrm{dl}(n=5)$, and $892 \pm 78 \mathrm{mg} / \mathrm{dl}(n=4)$ in the mIL- $8 \mathrm{RH}+/+$ BMT and mIL-8RH-/- BMT subgroups, respectively. The mean aortic valve lesional areas in these subgroups of animals were $601,203 \pm 91,861 \mu \mathrm{m}^{2}$ for the mIL-8RH+/+ BMT mice and $333,095 \pm 195,711 \mu \mathrm{m}^{2}$ for the mIL-8RH-/- BMT mice $(P=$ 0.02 by the Mann-Whitney test). This persistent difference in lesion area in animals with similar cholesterol levels suggested that factors other than plasma cholesterol were contributing to the markedly diminished extent of atherosclerosis in mIL8RH-/- BMT mice.

Deficient recruitment of MOMA-2 positive macrophages after $m I L-8 R-/-B M T$. Immunohistochemical analysis of serial sections from animals matched for plasma cholesterol demonstrated that the aortic valve lesions of the mIL-8RH $+/+$ BMT mice expressed mIL-8RH (Fig. 8). The mIL-8RH staining in the lesions of these mIL-8RH+/+ BMT mice was widespread, intense, and restricted to cell-rich areas throughout the intima (Fig. 8). Staining of serial sections for MOMA-2, a marker specific for monocyte-macrophages (51), demonstrated that mIL-8RH and MOMA-2 were colocalized in the intima (Fig. 8). However, T lymphocyte staining was not detected in these advanced murine lesions (53) (Fig. 8). Smooth muscle cell-rich regions of the lesions were generally negative for mIL-8RH (Fig. 8), consistent with predominant mIL-8RH expression by the macrophages within these lesions.

Only background staining for mIL-8RH was detected in the lesions of the mice that received mIL-8RH-/- marrow. More importantly, mIL-8RH-/- BMT markedly affected the cellularity of the lesions. This was evidenced by weak intimal staining for MOMA-2 positive macrophages in these animals compared with the strong and dispersed MOMA-2 intimal staining in lesions after mIL-8RH+/+ BMT (Fig. 8).

Expression of the murine $I L-8$ receptor-binding $C-X-C$ chemokine $K C / G R O \alpha$. The association of the intralesional presence of mIL-8RH with more extensive monocyte-macrophage recruitment in $\mathrm{mIL}-8 \mathrm{RH}+/+$ BMT mice suggested the potential for direct involvement in atherosclerosis of $\mathrm{mIL}$ $8 \mathrm{RH}$ and at least one of its C-X-C chemokine ligands. Mice do not express an IL- 8 peptide homologue (45) but they do express the GRO $\alpha$ homologue $\mathrm{KC}$, and the GRO $\beta, \gamma$ homologue MIP-2, which are known to bind and activate mIL-8RH (43, 44). To examine the expression of $\mathrm{KC} / \mathrm{GRO} \alpha$ in the lesions, the heart valve sections were stained with a goat anti-mouse $\mathrm{KC}$ antibody. $\mathrm{KC} / \mathrm{GRO} \alpha$ was detected in the intimal macrophage-rich areas of atherosclerotic lesions in both groups of mice by immunohistochemistry (Fig. 9). Interestingly, some of the endothelial cells, as well as other cells found within the lesion, stained positively for $\mathrm{KC} / \mathrm{GRO} \alpha$ (Fig. 9). The identification of $\mathrm{KC} / \mathrm{GRO} \alpha$ in the lesions of both groups of mice, but mIL-8RH only in the lesions of mice whose leukocytes expressed mIL- $8 \mathrm{RH}+/+$ after BMT, suggested a key role for $\mathrm{KC} / \mathrm{GRO} \alpha$ and possibly other mIL-8RH-binding C-X-C chemokines in macrophage localization in these atheroclerotic lesions. 


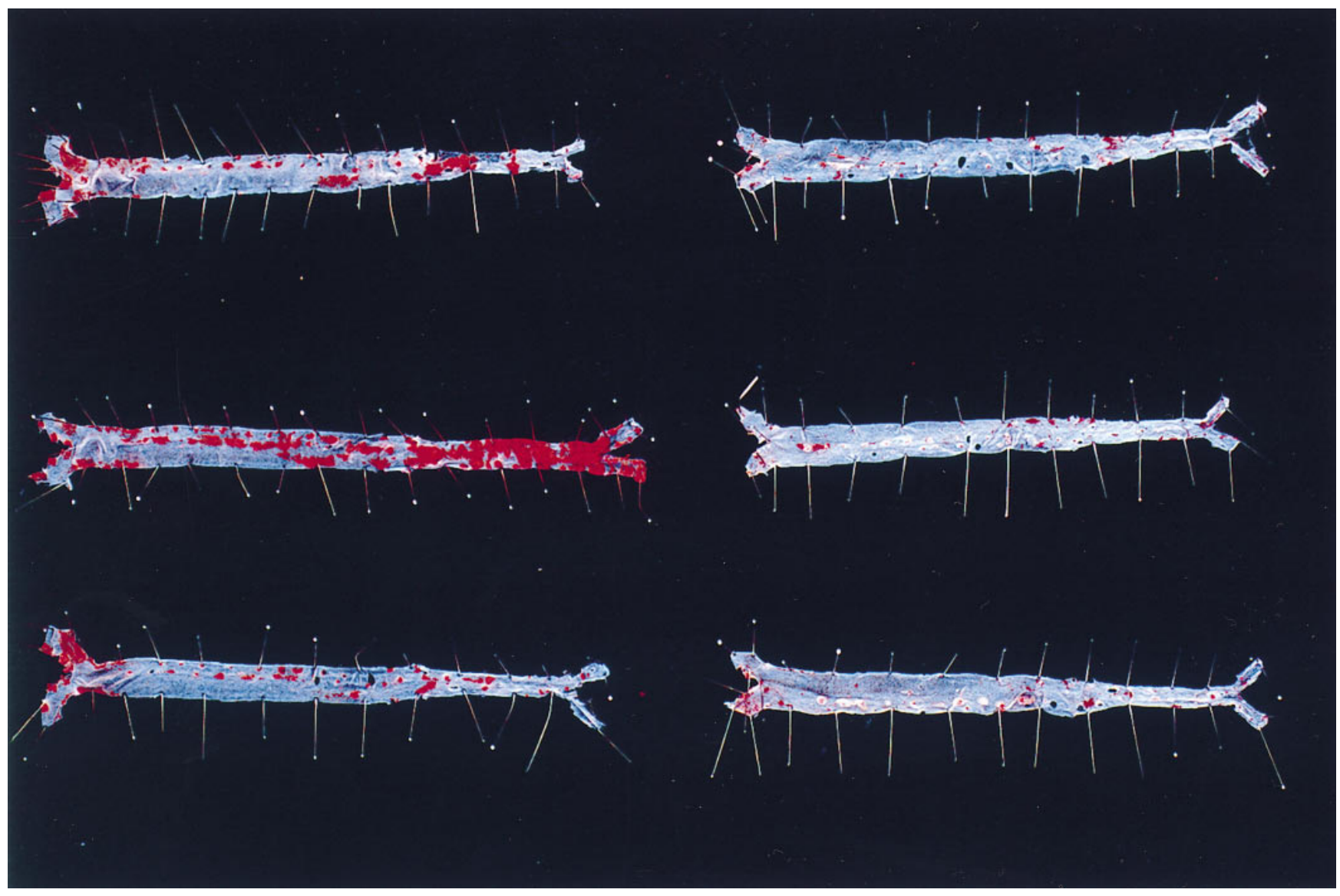

Figure 5. Sudan IV staining of atherosclerotic lesions in isolated aortas in LDLR-/- mice that received mIL-8RH-/- marrow versus mIL$8 \mathrm{RH}+/+$ marrow. Shown in this figure are three aortas each from mice that received either mIL- $8 \mathrm{RH}+/+\mathrm{BMT}$ (three aortas on the left) or mIL8RH-/- BMT (three aortas on the right) all of which were matched for similar plasma cholesterol levels (910-957 mg/dl). The aortas were dissected out after they were carefully stripped of the adventitial fat and stained with Sudan IV to reveal the raised atherosclerotic lesions in the lumen, shown here to be stained bright red. On all the aortas, the aortic arch is at the left end and the iliac bifurcation at the right end.

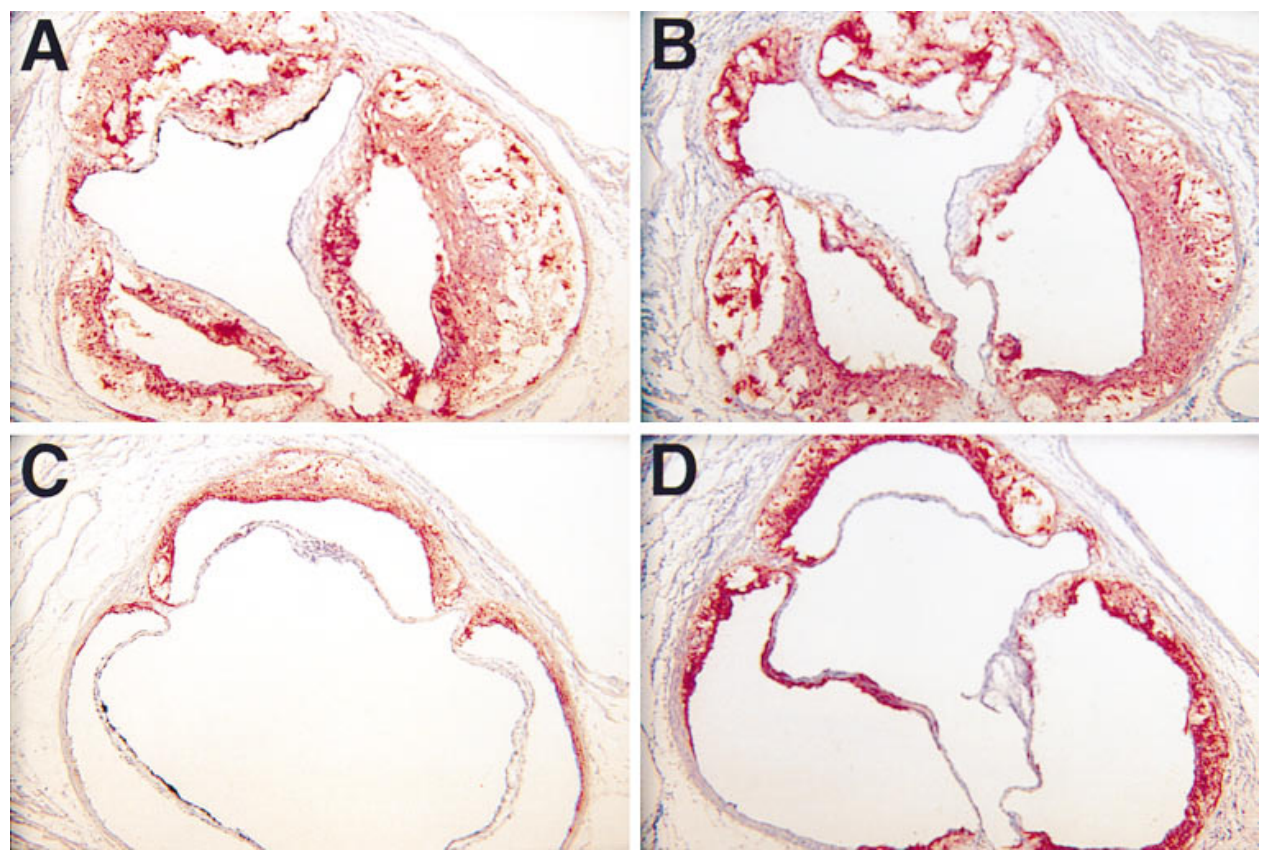

Figure 6. Representative oil red O-stained sections of aortic valves from two plasma cholesterolmatched mice in the two groups 20 wk after bone marrow transplantation (and 16 wk after starting the atherogenic diet). The cryosections were cut $10 \mu \mathrm{m}$ thick and stained to show the bright red staining of the atherosclerotic lesions. $A$ and $B$ are sections from recipients of mIL$8 \mathrm{RH}+/+$ BMT, characterized by advanced lesions with necrotic core, proliferated smooth muscle layer and cell-rich areas of the subendothelium. In contrast, lesions of mice that received mIL-8RH-/- BMT $(C$ and $D)$ are generally less advanced with a much smaller necrotic core and less prominent smooth muscle proliferation. 


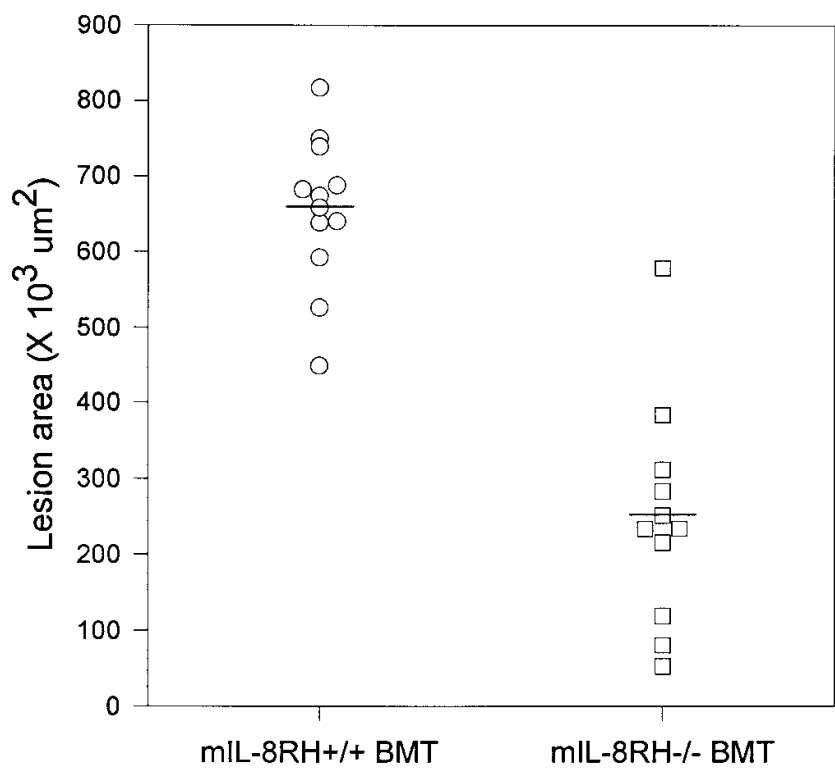

Figure 7. Quantification of size of aortic valve lesion areas. Oil red O-stained aortic valve lesion areas, such as those shown in Fig. 4, were quantified using a computer-assisted video imaging system. Each symbol represents the mean lesion area of five sections from the heart of each animal taken every $40 \mu \mathrm{m}$ through the aortic valve. The mean \pm SD lesion area of the recipients of mIL-8RH $+/+$ BMT $(n=$ 12) was $654,241+99,117 \mu \mathrm{m}^{2}$, whereas it was $249,581 \pm 147,197 \mu \mathrm{m}^{2}$ for the recipients of mIL-8RH-/- BMT $(n=11)$.

\section{Discussion}

Recent studies have suggested that IL-8, and certain other highly homologous $\mathrm{CXCR}-2$-binding $\mathrm{C}-\mathrm{X}-\mathrm{C}$ chemokines including GRO $\alpha$ (27), have the potential to modulate atherogenesis (19-23). In this study, we observed that the human IL-8 receptor CXCR-2 could be detected in the macrophage-rich intima in human carotid atherosclerotic lesions (Fig. 1). Furthermore, the murine homologue of the human IL-8 receptor CXCR-2 (mIL-8RH) (42-44) was abundant in macrophagerich areas of established aortic atherosclerotic lesions in LDLR $-/-$ mice fed an atherogenic diet for $16 \mathrm{wk}$ (Figs. 2 and $8)$. The functional importance of this receptor was confirmed by demonstration that its absence on bone marrow-derived peripheral blood leukocytes was associated with reduced lesion area (Figs. 5-7) associated with markedly reduced recruitment of mIL-8RH-positive and MOMA-2 positive intimal macrophages (Fig. 8). The results imply a direct role for IL-8 receptor-binding $\mathrm{C}-\mathrm{X}-\mathrm{C}$ chemokines in the localization of macrophages in atherosclerotic lesions.

This study identified that $\mathrm{KC} / \mathrm{GRO} \alpha(17,41,44)$ shares with IL-8 the potential to recruit cells to atherosclerotic lesions. Lesional $\mathrm{KC} / \mathrm{GRO} \alpha$ expression, which we evaluated because mice do not express IL-8 $(42,44,45)$, was generally abundant in the atherosclerotic lesions of LDL receptor-deficient mice, irrespective of the presence or absence of mIL$8 \mathrm{RH}$ expression by leukocytes (Fig. 8). Activated monocytemacrophages, endothelial cells, smooth muscle cells, and $\mathrm{T}$ lymphocytes all have the potential to produce IL- 8 and GRO $\alpha$ in vitro $(16,18,22,23,40,54-56)$, but in human atherosclerotic plaques IL-8 may be most prominently expressed in foam cells
$(20,21)$. We detected $\mathrm{KC} / \mathrm{GRO} \alpha$ staining of endothelium of aortic valve atherosclerotic lesions, but the predominant location of $\mathrm{KC} / \mathrm{GRO} \alpha$ was in the macrophage-rich intima (Fig. 8). Further investigation will be needed to ascertain if GRO $\alpha$ is expressed more widely than IL- 8 in human atherosclerotic lesions $(20,21)$. It will also be of interest to determine the relative contributions of M-CSF and other cytokines (1, 57-59), and of oxidized LDL $(20,22,23,60,61)$ to the induction of $\mathrm{KC} / \mathrm{GRO} \alpha$ and IL- 8 in atherosclerotic lesions.

Atherosclerotic lesions can contain many potential agents other than GRO $\alpha$ and IL-8 $(26,33,62)$ that can modulate monocyte adhesion and/or transmigration, including JE/MCP-1, and certain products of lipid oxidation released from oxidized LDL $(11,13)$. Thus, it was surprising to see that the accumulation of a fraction of intimal macrophages was dependent on the presence of mIL-8RH on bone marrow-derived leukocytes (Fig. 8). It is possible that mIL-8RH-mediated effects of $\mathrm{KC} / \mathrm{GRO} \alpha$ on monocyte adhesion to endothelium $(23,25)$, and monocyte-macrophage activation (37), retention and maturation (52) might jointly account for these effects. Though CXCR-2 and mIL-8RH expression have been reported to be an order of magnitude lower in normal circulating monocytes than in neutrophils (28-31), CXCR-2 expression can be upregulated by certain inflammatory cytokines and by leukocyte maturation in vitro $(26,32,38,39)$. Such effects likely account for the upregulated expression of CXCR-2 in some of the macrophages in chronic experimental granulation tissue (40), and may explain the unexpectedly prominent expression of mIL$8 \mathrm{RH}$ by MOMA-2 positive intimal macrophages in murine atherosclerotic lesions (Fig. 8). Thus, it will of interest to further define the basic mechanisms and precise functional consequences of enhanced monocyte-macrophage mIL-8RH/ CXCR-2 expression in vitro, and in vivo in atherosclerotic lesions.

IL-8 receptor-binding C-X-C chemokines are potent neutrophil chemotaxins $(17,18)$, but the atherosclerotic lesions of LDLR-/- mice that expressed $\mathrm{KC} / \mathrm{GRO} \alpha$ and $\mathrm{mIL}-8 \mathrm{RH}$ consistently demonstrate a scarcity of neutrophils $(1,46,47)$. Similarly, neutrophils are scarce in most human atherosclerotic lesions (1), despite the repeated detection in lesions of not only IL-8 (19-21) but also of E-Selectin, the major endothelial ligand for neutrophils (10). The paucity of neutrophils in atherosclerotic lesions that contain IL-8 receptors remains unexplained and counterintuitive. However, neutrophil emigration is a multi-step process, which requires synergistic interactions between specific chemotaxins, endothelial adhesion proteins, neutrophil integrins, and matrix constituents (63) that might be not be favored in atherosclerotic lesions. For example, human neutrophil chemotaxis in response to IL-8 requires nanomolar concentrations that are up to 10-fold higher than the IL-8 concentrations that cause T lymphocyte chemotaxis (26), and up to a thousand-fold higher than the IL-8 concentrations that cause endothelial cell chemotaxis (25). Alternatively, the scarcity of neutrophils in atherosclerotic lesions suggests the possibility that effects of CXCR-2-binding chemokines on the initial adhesion and emigration of leukocytes during lesion formation might be less significant than subsequent effects of such chemokines on the retention and activation of macrophages in established lesions that express upregulated CXCR-2 (Fig. 8).

The concentration of $\mathrm{T}$ lymphocytes is very low relative to that of macrophages in lesions that have reached the stage 

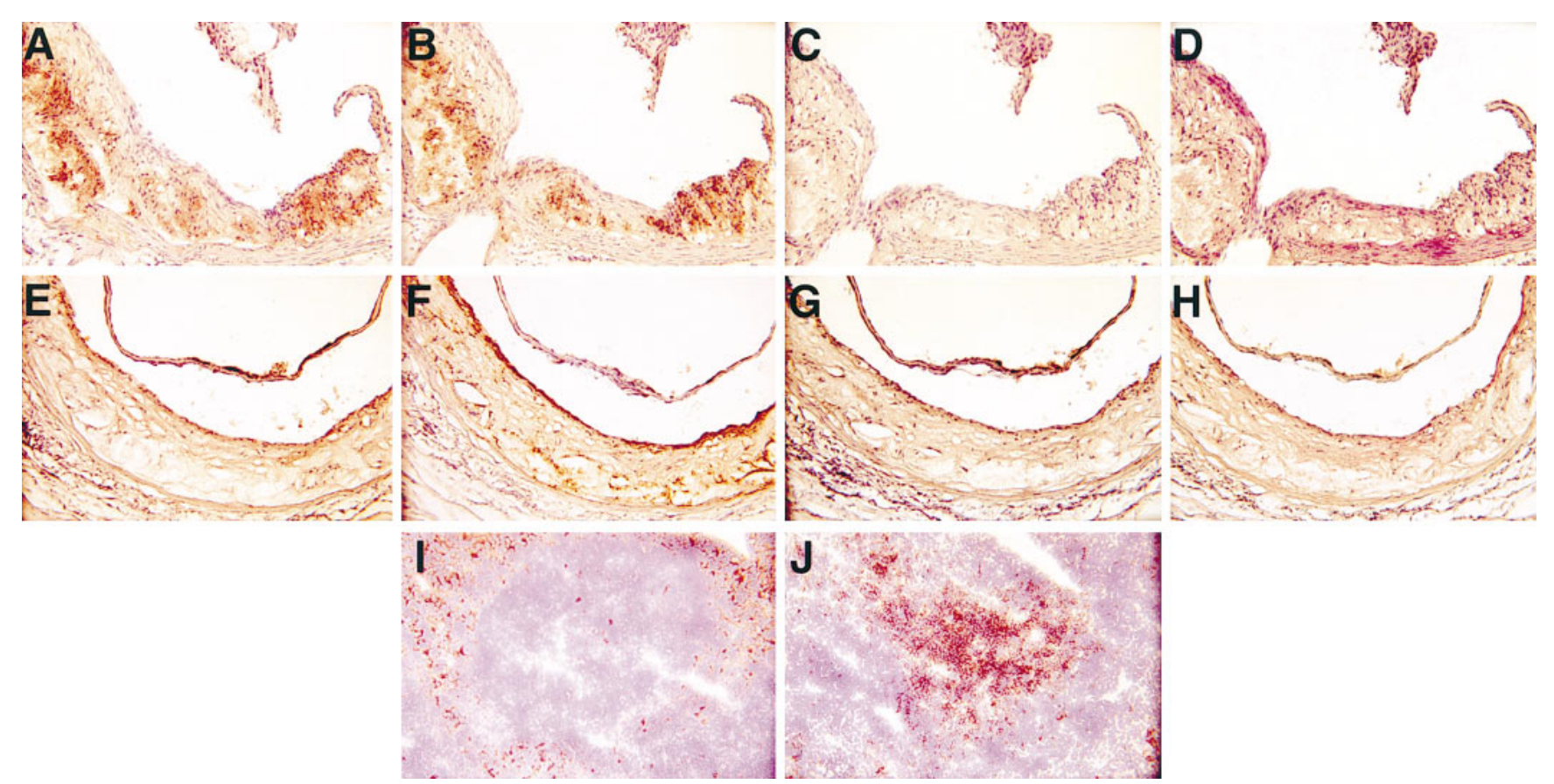

Figure 8. mIL-8RH colocalizes with the macrophage marker MOMA-2. Leukocyte mIL-8RH is necessary for the accumulation of MOMA-2 positive macrophages in aortic valve atherosclerotic lesions. Sections $(\times 130)$ from plasma cholesterol-matched $\mathrm{mIL}-8 \mathrm{RH}+/+\mathrm{BMT}$ recipients $(A-D)$ and mIL-8RH-/- BMT recipients $(E-H)$ were incubated with antibodies specific for mIL-8RH $(A$ and $E)$, MOMA-2 $(B$ and $F)$, CD4, CD8 $(C$ and $G)$, and the smooth muscle marker a-actin $(D$ and $H)$ and developed as described in Methods. $I$ and $J(\times 130)$ are specificity controls using sections of mouse spleen stained for MOMA-2 ( $I$, selective red pulp staining) and CD4, CD8 ( $J$, selective white pulp staining).
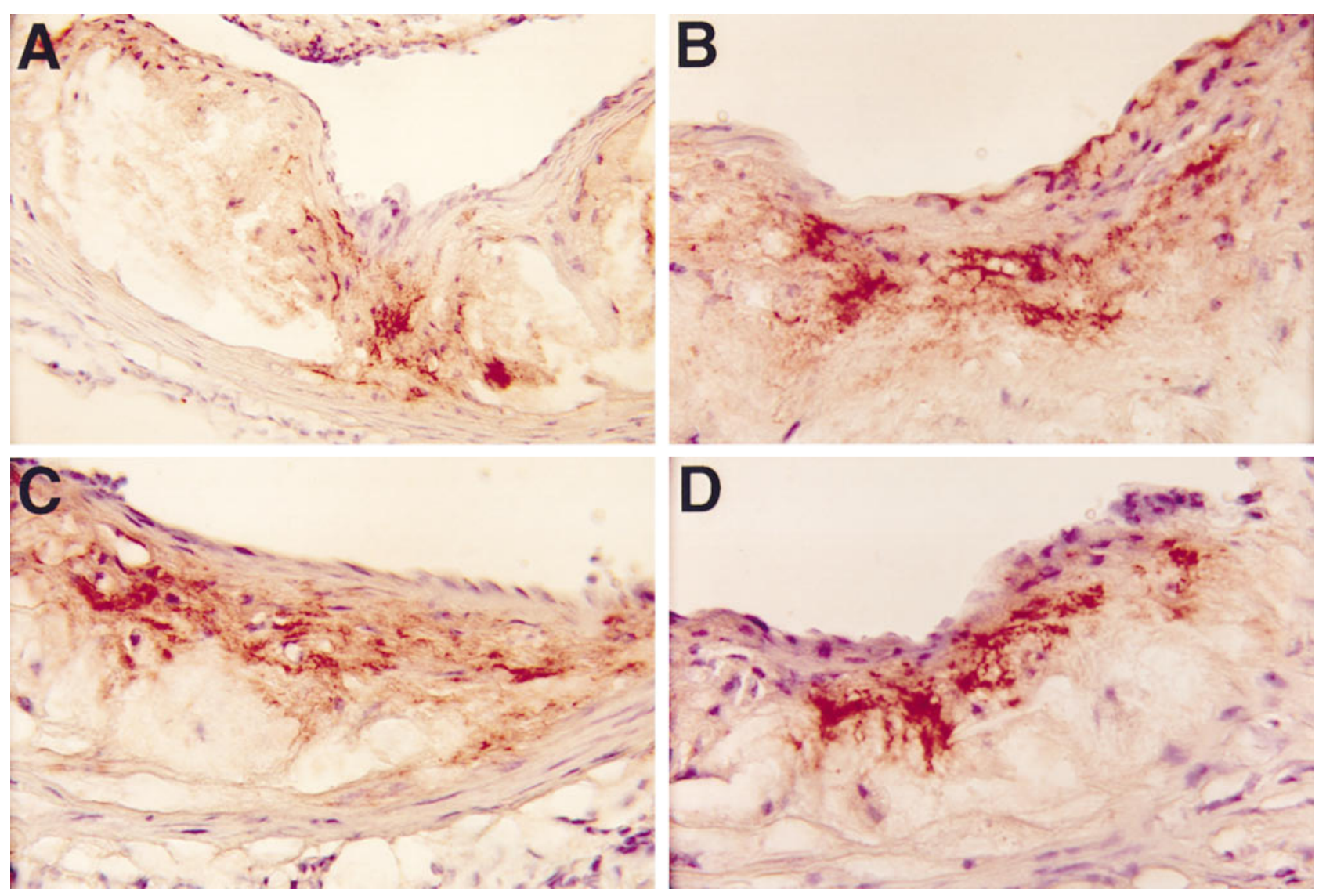

Figure 9. Immunohistochemical staining of aortic valve lesions for expression of KC/GRO $\alpha$. The cryo-sections of aortic valves in plasma-cholesterol matched animals were incubated with a goat anti-mouse KC polyclonal antibody and detected as described in Methods. $A$ and $B$ show sections from mice that received mIL-8RH+/+ BMT $(\times 200)$, whereas $C$ and $D$ show sections from mice that received mIL-8RH- - BMT $(\times 200)$. The majority of the positive staining is localized to the space immediately beneath the endothelium. 
where an extensive necrotic core has developed (53), and we detected no intimal $\mathrm{T}$ cell staining in the advanced murine atherosclerotic lesions examined in this study (Fig. 8). However, these findings do not exclude the possibility that earlier effects on $\mathrm{T}$ cells might influence monocyte-macrophage recruitment and retention. In this regard, IL- 8 and the IL- 8 receptor-binding chemokine GRO $\alpha$ act as chemoattractants for CD4+ and CD8+ T lymphocytes that express CD45RO $(26,27)$. Furthermore, CD45RO+ cells comprise the majority of T lymphocytes within atherosclerotic plaques (64).

Though animals lacking mature $\mathrm{T}$ cell function develop atherosclerosis $(5,6,9)$, it will be of interest to define the potential for IL-8 receptor-binding C-X-C chemokines to interact with $\mathrm{T}$ lymphocytes in atherosclerotic lesions. In this regard, the modulating effects of immune responses on atherogenesis appear variable $(7,8,53)$. One could speculate IL-8 receptorbinding $\mathrm{C}-\mathrm{X}-\mathrm{C}$ chemokines could contribute to the disparities observed in the $\mathrm{T}$ cell subsets and the predominant lesional $\mathrm{T}$ cell response (e.g., Th1 versus Th2 response $[56,65,66]$ ) in atherosclerotic lesions of different stages $(53,67)$. Examination of early and developing atherosclerotic lesions for the cellular patterns of expression of IL-8 receptor-binding C-X-C chemokines and IL-8 receptors, and further characterization of mIL-8RH-deficient animals also should be useful in defining the potential for CXCR-2 expression to directly affect the atherogenic role of other cells. In this regard, some endothelial cells (25) also expressed mIL-8RH in atherogenic lesions (Fig. $8)$, and smooth muscle cells have the capacity to express CXCR-2 (54).

In this study, the area (Fig. 7) and morphology (Fig. 6) of aortic and aortic valve atherosclerotic lesions were affected by the absence of mIL-8RH in bone marrow-derived leukocytes. This suggests a significant role in lesion progression for $\mathrm{KC} /$ GRO $\alpha$ and/or other IL-8 receptor binding C-X-C-chemokines, acting at the level of localization of mIL-8RH-bearing macrophages in lesions (Fig. 8). However, limitations to this study were evident. When the animals were fed the atherogenic diet, the plasma cholesterol in recipients of mIL-8RH-/- BMT was $\sim 30 \%$ lower than in recipients of mIL-8RH+/+ BMT (Fig. 3). As revealed by FPLC, this reduction was due to decreased cholesterol in all the lipoprotein fractions, especially in VLDL (Fig. 4). Body weight also was consistently 15\% lower in recipients of $\mathrm{mIL}-8 \mathrm{RH}-/-\mathrm{BMT}$. Although food intake was not recorded, there was no obvious difference in the amount of food consumed by the two groups of animals.

It is likely that certain characteristics of the mIL-8RH-/phenotype, including consequences of myeloid expansion such as organomegaly and the potential metabolic effects of disregulated cytokine production by the expanding myeloid tissues (42) may account for differences in the cholesterol levels and weight. The precise causes for these differences and the extent of their contribution to diminished atherosclerosis in recipients of mIL-8RH-/- BMT were not defined. However, it is unlikely that a $30 \%$ lower mean plasma cholesterol in recipients of mIL-8RH-/- BMT (Fig. 3) would by itself cause a more marked 2.5-fold reduction in lesion area (Fig. 7). First, when subsets of animals from both groups with similar plasma cholesterol levels were analyzed, the extent of aortic lesions was far less after mIL-8RH-/- BMT (Figs. 5 and 6). Second, the mean lesion area of recipients of mIL-8RH-l- BMT also was twofold less than in recipients of mIL- $8 \mathrm{RH}+/+$ BMT with approximately equal plasma cholesterol values $(P=0.02)$. Third, the histology of atherosclerotic lesions differed according to the phenotype of the bone marrow donor in animals with equivalent plasma cholesterols. Specifically, lesions in recipients of mIL-8RH-/- BMT had not only diminished macrophage recruitment but also evidence for less extensive necrotic cores and smooth muscle proliferation (Figs. 6, 8, and 9).

In conclusion, this study indicated that leukocyte mIL-8RH expression plays a significant role in the localization of macrophages in atherosclerotic lesions and the progression of such lesions in LDLR-/- mice. We anticipate that future investigation of the roles of mIL-8RH/CXCR-2 and its ligands in atherosclerotic lesions will yield additional insights into atherogenesis, and possibly provide new rational therapeutic targets.

\section{Acknowledgments}

We gratefully acknowledge helpful advice and donation of mIL$8 \mathrm{RH}-/+$ mice by Dr. Mark Moore and Dr. Grace Cacolano of Genentech (South San Francisco, CA). Dr. Ingrid Schraufstatter of The Scripps Research Institute generously provided an antibody specific for human CXCR-2. We also acknowledge the technical assistance of Audrey S. Black, Peter Sears, David Rohnow, and Kristen Johnson. Dr. Robert Kaplan of the University of California at San Diego (UCSD) provided helpful advice for the statistical analyses.

This work was supported by National Institutes of Health grants HL-35297 (L.K. Curtiss), HL-57934 (W.A. Boisvert), and AG-O7996 (R.A. Terkeltaub), and awards from the Department of Veterans Affairs, Arthritis Foundation, and the Stein Institute for Research on Aging, UCSD.

\section{References}

1. Ross, R. 1993. The pathogenesis of atherosclerosis: perspective for the 1990's. Nature. 362:801-809.

2. Ridker, P.M., M. Cushman, M.J. Stampfer, R.P. Tracy, and C.H. Hennekens. 1997. Inflammation, aspirin, and the risk of cardiovascular disease in apparently healthy men. N. Engl. J. Med. 336:973-979.

3. Watanabe, T., S. Haraoka, and T. Shimokama. 1996. Inflammatory and immunological nature of atherosclerosis. Int. J. Cardiol. 54(Suppl.):S51-S60.

4. Stemme, S., B. Faber, J. Holm, O. Wiklund, J.L. Witztum, and G.K Hansson. 1995. T lymphocytes from human atherosclerotic plaques recognize oxidized low density lipoprotein. Proc. Natl. Acad. Sci. USA. 92:3893-3897.

5. Fyfe, A.I., J.-H., Qiao, and A.J. Lusis. 1994. Immune-deficient mice develop typical atherosclerotic fatty streaks when fed an atherogenic diet. J. Clin. Invest. 94:2516-2520.

6. Dansky, H.M., S.A. Charlton, M.M. Harper, and J.D. Smith. 1997. T and B lymphocytes play a minor role in atherosclerotic plaque formation in the apolipoprotein E-deficient mouse. Proc. Natl. Acad. Sci. USA. 94:4642-4646.

7. Palinski, W., E. Miller, and J.L. Witztum. 1995. Immunization of low density lipoprotein (LDL) receptor-deficient rabbits with homologous malondialdehyde-modified LDL reduces atherogenesis. Proc. Natl. Acad. Sci. USA. 92: 821-825.

8. Gupta, S., A.M. Pablo, X.-C. Jiang, N. Wang, A.R. Tall, and C. Schindler. 1997. IFN- $\gamma$ potentiates atherosclerosis in apoE knock-out mice. J. Clin. Invest. 99:2752-2761.

9. Daugherty, A., E. Pure, D. Delfel-Butteiger, S. Chen, J. Leferovich, S.E. Roselaar, and D.J. Rader. 1997. The effects of total lymphocyte deficiency on the extent of atherosclerosis in apolipoprotein E-/- mice. J. Clin. Invest. 100: 1575-1580.

10. Tenaglia, A.N., A.J. Buda, R.G. Wilkins, M.K. Barron, P.R. Jeffords, K. Vo, M.O. Jordan, B.A. Kusnick, and D.J. Lefer. 1997. Levels of expression of P-selectin, E-selectin, and intercellular adhesion molecule-1 in coronary atherectomy specimens from patients with stable and unstable angina pectoris. Am. J. Cardiol. 79:742-747.

11. Watson A.D., N. Leitinger, M. Navab, K.F. Faull, S. Horkko, J.L. Witztum, W. Palinski, D. Schwenke, R.G. Salomon, W. Sha, et al. 1997. Structural identification by mass spectrometry of oxidized phospholipids in minimally oxidized low density lipoprotein that induce monocyte/endothelial interactions and evidence for their presence in vivo. J Biol. Chem. 272:13597-13607.

12. Frostegard, J., Y.H. Huang, J. Ronnelid, and L. Schafer-Elinder. 1997. Platelet-activating factor and oxidized LDL induce immune activation by a common mechanism. Arterioscler. Thromb. Vasc. Biol. 17:963-968.

13. Prescott, S.M., T.M. McIntyre, G.A. Zimmerman, and D.M. Stafforini. 
1996. Inflammation as an early component of atherosclerosis and vascular damage-a role for P-selectin and platelet-activating factor. Jpn. Circ. J. 60:137-141.

14. Yla-Herttula, S., B.A. Lipton, M.E. Rosenfeld, T. Sarkioja, T. Yoshimura, E.J. Leonard, J.L. Witztum, and D. Steinberg. 1991. Expression of monocyte chemoattractant protein 1 in macrophage-rich areas of human and rabbit atherosclerotic lesions. Proc. Natl. Acad. Sci. USA. 88:5252-5256.

15. Navab, M., S.S. Imes, S.Y. Hama, G.P. Hough, L.A. Ross, R.W. Bork, A.J. Valente, J.A. Berliner, D.C. Drinkwater, H. Laks, and A.M Fogelman. 1991. Monocyte transmigration induced by modification of low density lipoprotein in cocultures of human aortic wall cells is due to induction of monocyte chemotactic protein 1 synthesis and is abolished by high density lipoprotein. $J$. Clin. Invest. 88:2039-2046.

16. Howard, O.M., A. Ben-Baruch, and J.J. Oppenheim. 1996. Chemokines: progress toward identifying molecular targets for therapeutic agents. Trends Biotechnol. 14:46-51.

17. Ahuja, S.K., and P.M. Murphy. 1996. The CXC chemokines growth-regulated oncogene (GRO) alpha, GRObeta, GROgamma, neutrophil-activating peptide-2, and epithelial cell-derived neutrophil-activating peptide-78 are potent agonists for the type $\mathrm{B}$, but not the type $\mathrm{A}$, human interleukin- 8 receptor. J. Biol. Chem. 271:20545-20550.

18. Hoch, R.C., I.U. Schraufstatter, and C.G. Cochrane. 1996. In vivo, in vitro, and molecular aspects of interleukin- 8 and the interleukin- 8 receptors. $J$. Lab. Clin. Med. 128:134-145.

19. Koch, A.E., S.L. Kunkel, W.H. Pearce, M.R. Sha, D. Parikh, H.L. Evanoff, G.K. Haines, M.D. Burdick, and R.M. Strieter. 1993. Enhanced production of the chemotactic cytokines interleukin- 8 and monocyte chemoattractant protein-1 in human abdominal aortic aneurysms. Am. J. Pathol 142:14231431.

20. Wang, N., I. Tabas, R. Winchester, S. Ravalli, L.E. Rabbani, and A. Tall. 1996. Interleukin 8 is induced by cholesterol loading of macrophages and expressed by macrophage foam cells in human atheroma. J. Biol. Chem. 271: 8837-8842.

21. Apostolopoulos, J., P. Davenport, and P.G. Tipping. 1996. Interleukin-8 production by macrophages from atheromatous plaques. Arterioscler. Thromb. Vasc. Biol. 16:1007-1012.

22. Terkeltaub, R., C. Banka, J. Solan, D. Santoro, K. Brand, and L.K. Curtiss. 1994. Oxidized LDL induces the expression by monocytic cells of IL-8, a chemokine with T lymphocyte chemotactic activity. Arterioscler. Thromb. 14: $47-53$.

23. Schwartz, D., A. Andalibi, L. Chaverri-Almada, J.A. Berliner, T. Kirchgessner, Z.-T. Fang, P. Tekamp-Olson, A.J. Lusis, C. Gallegos, A.M. Fogelman, and M.C. Territo. 1994. Role of the GRO family of chemokines in monocyte adhesion to MM-LDL-stimulated endothelium. J. Clin. Invest. 94:1968-1973.

24. Murakami, K., A. Ueno, K. Yamanouchi, and T. Kondo. 1995. Thrombin induces GRO alpha/MGSA production in human umbilical vein endothelial cells. Thromb. Res. 79:387-394.

25. Koch, A.E., P.J. Polverini, S.L. Kunkel, L.A. Harlow, L.A. DiPietro, V.M. Elner, S.G. Elner, and R.M. Strieter. 1992. Interleukin-8 as a macrophage-derived mediator of angiogenesis. Science. 258:17998-18001.

26. Xu, L, D.J. Kelvin, G.Q. Ye, D.D. Taub, A. Ben-Baruch, J.J. Oppenheim, and J.M. Wang. 1995. Modulation of IL-8 receptor expression on purified human lymphocytes is associated with changed chemotactic responses to IL-8. J. Leukocyte Biol. 57: 335-342.

27. Jinquan, T., J. Frydenberg, N. Mukaida, J. Bonde, C.G. Larsen, K. Matsushima, and K. Thestrup-Pedersen. 1995. Recombinant human growth-regulated oncogene-alpha induces $\mathrm{T}$ lymphocyte chemotaxis. A process regulated via IL-8 receptors by IFN-gamma, TNF-alpha, IL-4, IL-10, and IL-13. J. Immunol. 155:5359-5368.

28. Morohashi, H., T. Miyawaki, H. Nomura, K. Kuno, S. Murakami, K. Matsushima, and N. Mukaida. 1995. Expression of both types of human interleukin-8 receptors on mature neutrophils, monocytes, and natural killer cells. $J$. Leukocyte Biol. 57:180-187.

29. Wang, J., Y. Zhang, T. Kasahara, A. Harada, K. Matsushima, and N. Mukaida. 1996. Detection of mouse IL-8 receptor homologue expression on peripheral blood leukocytes and mature myeloid lineage cells in bone marrow. $J$. Leukocyte Biol. 60:372-381.

30. Chuntharapai, A., J. Lee, C.A. Hebert, and K.J. Kim. 1994. Monoclonal antibodies detect different distribution patterns of IL-8 receptor A and IL-8 receptor B on human peripheral blood leukocytes. J. Immunol. 153:5682-5688.

31. Quin, S., G. LaRosa, J.J. Campbell, H. Smith-Health, N. Kassam, X. Shi, L. Zeng, E.C. Butcher, and C.R. Mackay. 1996. Expression of monocyte chemoattractant protein- 1 and interleukin- 8 receptors on subsets of T cells: correlation with transendothelial chemotactic potential. Eur. J. Immunol. 26:640647.

32. Zahn, S., Z. Jorj, H.-P. Spanger, and O. Gotze. 1997. Chemoattractant receptors for interleukin-8 and $\mathrm{C} 5 \mathrm{a}$ : expression on peripheral blood leukocytes and differential regulation on HL-60 and AML-193 cells by vitamin $\mathrm{D}_{3}$ and alltrans retinoic acid. Eur. J. Immunol. 27:935-940.

33. Santamaria Babi, L.F., B. Moser, M.T. Perez Soler, R. Moser, P. Loetscher, B. Villiger, K. Blaser, and C. Hauser. 1996. The interleukin-8 receptor B and $\mathrm{CXC}$ chemokines can mediate transendothelial migration of human skin homing T cells. Eur. J. Immunol. 26:2056-2061.
34. Lloyd, A.R., J.J. Oppenheim, D.J. Kelvin, and D.D. Taub. 1996. Chemokines regulate $\mathrm{T}$ cell adherence to recombinant adhesion molecules and extracellular matrix proteins. J. Immunol. 156:932-938.

35. Lundahl, J., C.M. Skold, G. Hallden, M. Hallgren, and A. Eklund. 1996. Monocyte and neutrophil adhesion to matrix proteins is selectively enhanced in the presence of inflammatory mediators. Scand. J. Immunol. 44:143-149.

36. Brown, K.A., F. Le Roy, G. Nobel, K. Bacon, R. Camp, A. Vora, and D.C. Dumonde. 1990. Interleukin 8 acts on monocytes to increase their attachment to cultured endothelium and enhance their expression of surface adhesion molecules. Abstracts, 2nd International Symposium on Chemotactic Cytokines, London.

37. Walz, A., F. Meloni, I. Clark-Lewis, V. von Tscharner, and M. Baggiolini. 1991. $\mathrm{Ca}^{2+}$ changes and respiratory burst in human neutrophils and monocytes induced by NAP-1/Interleukin-8, NAP-2, and gro/MGSA. J. Leukocyte Biol. 50:279-286.

38. Sprenger, H., A.R. Lloyd, and D.J. Kelvin. 1995. Promoter analysis of the human interleukin-8 receptor genes, IL-8RA and IL-8RB. Immunobiology. 193:334-340.

39. Lloyd, A.R., A. Biragyn, J.A. Johnston, D.D. Taub, L. Xu, D. Michiel, H. Sprenger, J.J. Oppenheim, and D.J. Kelvin. 1995. Granulocyte-colony stimulating factor and lipopolysaccharide regulate the expression of interleukin 8 receptors on polymorphonuclear leukocytes. J. Biol. Chem. 270:28188-28192.

40. Nanney, L.B., S.G. Mueller, R. Bueno, S.C. Peiper, and A. Richmond. 1995. Distributions of melanoma growth stimulatory activity of growth-regulated gene and the interleukin- 8 receptor B in human wound repair. Am. J. Pathol. 147:1248-1260.

41. Ahuja, S.K., J.C. Lee, and P.M. Murphy. 1996. CXC chemokines bind to unique sets of selectivity determinants that can function independently and are broadly distributed on multiple domains of human interleukin-8 receptor B. Determinants of high affinity binding and receptor activation are distinct. $J$. Biol. Chem. 271:225-232.

42. Cacalano, G., J. Lee, K. Kikly, A.M. Ryan, S. Pitts-Meek, B. Hutgren, W.I. Wood, and M.W. Moore. 1994. Neutrophil B cell expansion in mice that lack murine IL-8 receptor homolog. Science. 265:682-684

43. Lee, J., G. Cacalano, T. Camerato, K. Toy, M.W. Moore, and W.I. Wood. 1995. Chemokine binding and activities mediated by the mouse IL- 8 receptor. J. Immunol. 155:2158-2164.

44. Bozic, C.R., N.P. Gerard, C. von Uexkull-Guldenband, L.F. Kolakowski, Jr., M.J. Conklyn, R. Breslow, H.J. Showell, and C. Gerard. 1994. The murine interleukin 8 type $\mathrm{B}$ receptor homologue and its ligands. Expression and biological characterization. J. Biol. Chem. 269:29355-29358.

45. Dunstan, C.A.N., M.N. Salafranca, S. Adhikari, Y. Xia, L. Feng, and J.K. Harrison. 1996. Identification of two rat genes orthologous to the human interleukin-8 receptors. J. Biol. Chem. 271:32770-32776.

46. Ishibashi, S., J.L. Goldstein, M.S. Brown, J. Herz, and D.K. Burns. 1994 Massive xanthomatosis and atherosclerosis in cholesterol-fed low density lipoprotein receptor-negative mice. J. Clin. Invest. 93:1885-1893.

47. Boisvert, W.A., J. Spangenberg, and L.K. Curtiss. 1997. Role of leukocyte-specific LDL receptors on plasma lipoprotein cholesterol and atherosclerosis in mice. Arterioscler. Thromb. Vasc. Biol. 17:340-347.

48. Boisvert, W.A., J. Spangenberg, and L.K. Curtiss. 1995. Treatment of severe hypercholesterolemia in apolipoprotein E-deficient mice by bone marrow transplantation. J. Clin. Invest. 96:1118-1124.

49. Tangirala, R.K., E.M. Rubin, and W. Palinski. 1995. Quantitation of atherosclerosis in murine models: correlation between lesions in the aortic origin and in the entire aorta, and differences in the extent of lesions between sexes in LDL receptor-deficient and apolipoprotein E-deficient mice. J. Lipid Res. 36:2320-2328.

50. Norgauer, J., B. Metzner, and I. Schraufstatter. 1996. Expression and growth-promoting function of the IL-8 receptor B in human melanoma cells. $J$. Immunol. 156:1132-1137.

51. Leenen, P.J., M.F. de Bruijn, J.S. Voerman, P.A. Campbell, and W. van Ewijk. 1994. Markers of mouse macrophage development detected by monoclonal antibodies. J. Immunol. Methods. 174:5-19.

52. Broxmeyer, H.E., S. Cooper, G. Cacalano, N.L. Hague, E. Bailish, and M.W. Moore. 1996. Involvement of Interleukin (IL) 8 receptor in negative regulation of myeloid progenitor cells in vivo: evidence from mice lacking the murine IL-8 receptor homologue. J. Exp. Med. 184:1825-1832.

53. Roselaar, S.E., P.X. Kakkanathu, and A. Daugherty. 1996. Lymphocyte populations in atherosclerotic lesions of apoE $-/-$ and LDL receptor $-/-$ mice. Decreasing density with disease progression. Arterioscler. Thromb. Vasc. Biol. 16:1013-1018.

54. Ming Wang, J., A. Sica, G. Peri, S. Walter, I.M. Padra, P. Libby, M Ceska, L.I. Lindley, F. Colotta, and A. Mantovani. 1991. Expression of monocyte chemotactic protein and interleukin- 8 by cytokine-activated human vascular smooth muscle cells. Arterioscler. Thromb. 11:1166-1174.

55. Schonbeck, U., E. Brandt, F. Petersen, H.D. Flad, and H. Loppnow. 1995. IL-8 specifically binds to endothelial but not to smooth muscle cells. $J$. Immunol. 154:2375-2383.

56. Kunkel, S.L. 1996. Th1- and Th2-type cytokines regulate chemokine expression. Biological Signals. 5:197-202.

57. Hashimoto, S., M. Yoda, M. Yamada, N. Yanai, T. Kawashima, and K. 
Motoyoshi. 1996. Macrophage colony-stimulating factor induces interleukin-8 production in human monocytes. Exp. Hematol. 24:123-128.

58. Anisowicz, A., M. Messineo, S.W. Lee, and R. Sager. 1991. An NF-кBlike transcription factor mediates IL-1/TNF- $\alpha$ induction of gro in human fibroblasts. J. Immunol. 147:520-527.

59. Lotz, M., R. Terkeltaub, and P.M. Villiger. 1992. Chondrocytes and joint inflammation: regulation of IL-8 expression in human articular chondrocytes. J. Immunol. 148:466-473.

60. Hamilton, T.A., and J.A. Major. 1996. Oxidized LDL potentiates LPSinduced transcription of the chemokine KC gene. J. Leukocyte Biol. 59:940947.

61. Liao, F., A. Andalibi, F.C. deBeer, A.M. Fogelman, and A.J. Lusis. 1993. Genetic control of inflammatory gene induction and NF-kappa B-like transcription factor activation in response to an atherogenic diet in mice. $J$. Clin. Invest. 91:2572-2579.

62. Murphy, W.J., Z.G. Tian, O. Asai, S. Funakoshi, P. Rotter, M. Henry, R.M. Strieter, S.L. Kunkel, D.L. Longo, and D.D. Taub. 1996. Chemokines and $\mathrm{T}$ lymphocyte activation. II. Facilitation of human $\mathrm{T}$ cell trafficking in severe combined immunodeficiency mice. J. Immunol. 156:2104-2111.

63. Lasky, L.A. 1992. Selectins: interpreters of cell-specific carbohydrate information during inflammation. Science. 258:964-969.

64. Stemme, S., J. Holm, and G.K. Hansson. 1992. T lymphocytes in human atherosclerotic plaques are memory cells expressing CD45RO and integrin VLA-1. Arterioscler. Thromb. 12:206-211.

65. Uyemura, K, L.L. Demer, S.C. Castle, D. Jullien, J.A. Berliner, M.D. Gately, R.R. Warrier, N. Pham, A.M. Fogelman, and R.L. Modlin. 1996. Crossregulatory roles of interleukin (IL)-12 and IL-10 in atherosclerosis. J. Clin. Invest. 97:2130-2138.

66. Jinquan, T., C.G. Larsen, B. Gesser, K. Matsushima, and K. ThestrupPedersen. 1993. Human IL-10 is a chemoattractant for CD8+ T lymphocytes and an inhibitor of IL-8-induced CD4+ T lymphocyte migration. J. Immunol. $151: 4545-4551$.

67. Drew, A.F., and P.G. Tipping. 1995. T helper cell infiltration and foam cell proliferation are early events in the development of atherosclerosis in cholesterol-fed rabbits. Arterioscler. Thromb. Vasc. Biol. 15:1563-1568. 